\title{
Publishing in English or another language: An inclusive study of scholar's language publication preferences in the natural, social and interdisciplinary sciences
}

\author{
Authors: Daniel Stockemer ${ }^{1}$, Michael J. Wigginton ${ }^{2}$
}

Affiliations: ${ }^{1}$ School of Political Studies, University of Ottawa, Room FSS7005, 120 University Private, Ottawa ON K1N 6N5, email: daniel.stockemer@uottawa.ca

${ }^{2}$ School of Political Studies, University of Ottawa, Room FSS7005, 120 University Private, Ottawa ON K1N 6N5, email: michael.wigginton@uottawa.ca

Online Publication: January $3^{\text {rd }}, 2019$

This is a post-peer-review, pre-copyedit version of an article published in Scientometrics. The final authenticated version is available online at: http://dx.doi.org/10.1007/s11192-018-2987-0 Please do not cite this version.

Abstract: To what extent has English become the dominant language of scientific communication? What factors push non-native speakers to publish their research in English rather than their native language? Using a survey of more than 800 authors of scientific papers in Springer Nature journals we find that the average non-anglophone researcher makes approximately $60 \%$ of their journal submissions in English. This percentage varies across disciplines, regions, and age groups, with younger scholars, Europeans, and those in the natural sciences favouring English more heavily. Finally, we find that the belief that publishing in English will increase the reputation of one's work is a primary motivator; in contrast, perceived institutional pressures to publish in English do not seem to influence researchers' language choice.

Key Words: Scientific communication, academic publishing, multilingual scholars, language of science, English as an international language

Acknowledgments: We thank Springer Nature for allowing us to use their survey on language choice in academic publications for this short article. 
While as recently as the mid $20^{\text {th }}$ century academic publishing and teaching in languages other than English was commonplace, the dominance of US and UK universities has made English the dominant language of international scholarship (Altbach 2007). This dominance of English as the common language of scientific communication has triggered some academic interest (see: Uzuner 2008). For example, several scholars highlight how the difficulty of mastering English and the preference for the writing styles of native speakers limit the ability of non-native speakers of English to produce or consume academic literature (Benfield and Howard 2000; Braine 2002; Flowerdew 2001, 2008, 2012; Flowerdew and Li 2009). Others raise concerns regarding the possibility that the use of English privileges western social networks and cultural norms, and thus further limits the participation of scholars from developing nations (Canagarajah 1996, 1999; Curry and Lillis 2010). A third group of studies has a slightly different focus and investigates the motivations of scholars to write in English rather than in their native language; in this type of research, there seems to be consensus that the prestige and international recognition of English-language journals is the primary motivation for non-native speakers to write their papers in English instead of their local language (Cho 2004; Curry and Lillis 2004; Duszak and Lewkowicz 2008; Lee and Lee 2013; López-Navarro et al. 2015; Rocher and Stockemer 2017) Finally, many studies highlight that in countries such as the Netherlands, Belgium and Turkey national policies have favored English by pushing publications in international journals as a requirement for funding and promotion (Işsk-Taş 2018; Uysal 2014).

While much has been written of the effects of English's dominance, the extent to which scholars favour English and the factors that lead them to do so has seen very little large-scale quantitative study; the literature lacks an analysis of the actual extent to which English dominates academic publishing. ${ }^{1}$ What percentage of their journal articles do non-native speakers write in English? Is there variation in scholars' tendencies to publish in English across disciplines, age groups, and motivational factors? This short research note tries to answer these questions. To do so, we use a survey of 856 non-native English-speaking researchers publishing in Springer journals in all disciplines that was undertaken to better understand researchers' habits in publishing and reading research. The survey, which was distributed to authors who published in Springer journals in either English or their native language, was available in six languages: English, Portuguese, Japanese, Korean, Chinese, and German. The survey was in the field from early October to late November 2016. Respondents were asked both closed- and open-ended questions about types of journals they publish in, the language(e)s they choose to adopt when writing and publishing their research, and their reasons for doing so. Roughly half of the respondents answered the survey in English.

Figure 1 confirms that English is the 'common language of science' or the most-used language of the scientific publication. ${ }^{2}$ Yet, its dominance in article-submissions is far from complete, at least when it comes to the results of our survey. On average, respondents estimate that $59.5 \%$ of their recent journal submissions are written in English, and only $16 \%$ report submitting exclusively in English. With a standard deviation of 29.5 the data are quite widely

\footnotetext{
${ }^{1}$ In fact, there is only one study by López-Navarro et al. (2015) that looks at the language choice of researchers using a large-scale survey. Yet, their results are limited to Spanish post-doctoral researchers, and do not provide a global overview.

${ }^{2}$ Indeed, according to Google Scholar (2018), the top 100 English-language journals have h5 indexes between 116362, compared to only 22-45 for Chinese, 14-38 for Spanish, and 5-14 for Japanese.
} 
spread. For example, roughly 20 percent of respondents estimate that they wrote a quarter or fewer of their recent submissions in English.

Fig. 1 Self-reported proportion of journal submissions written in English (last 3 years)

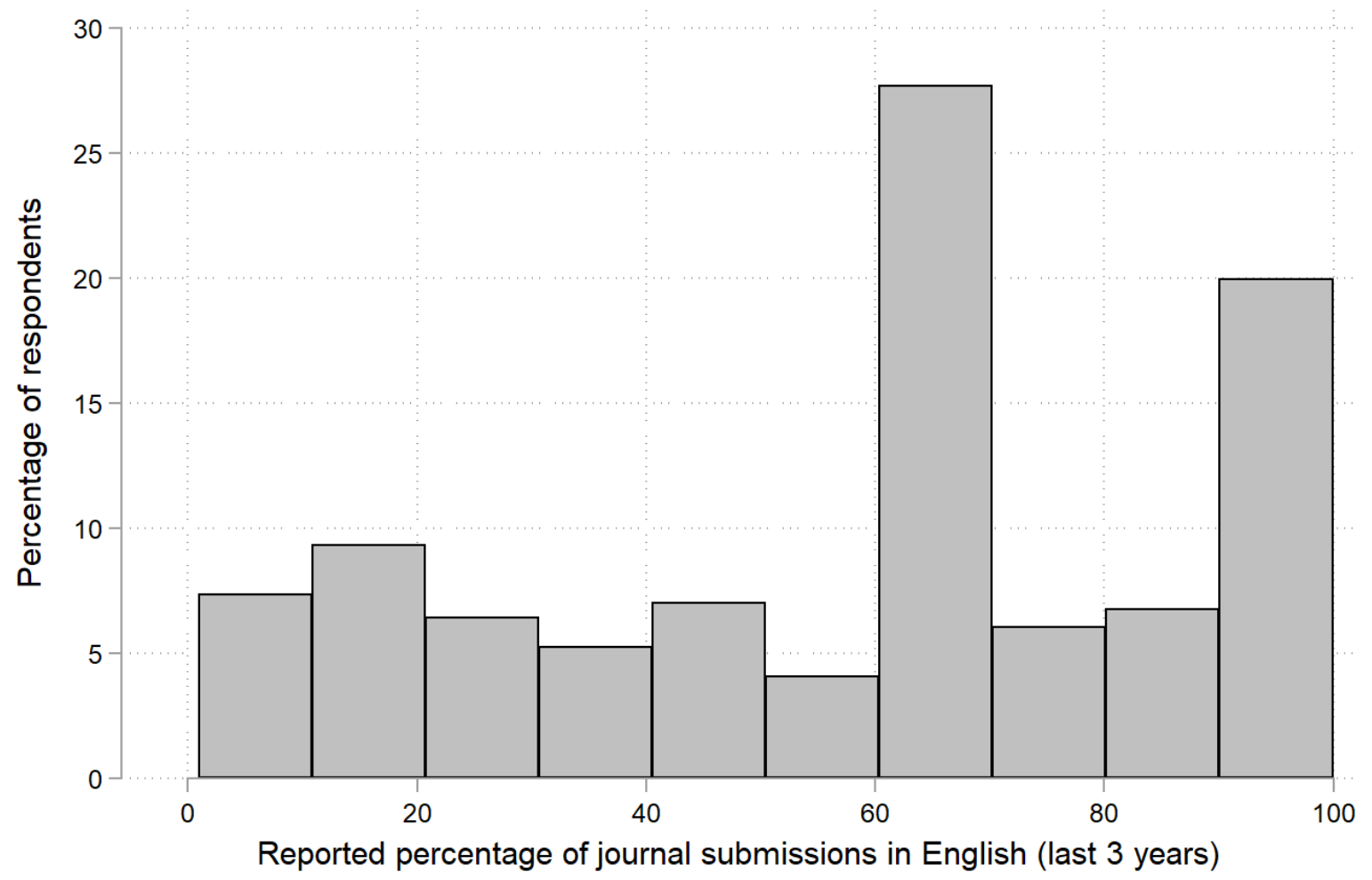

To explain the variation in scholars' tendency to publish in English, we perform bivariate tests on six possible explanatory variables: age, perceived reputation of English as the language of science, perceived institutional pressure to publish in English, place of employment, area of study (i.e. natural-, social- and interdisciplinary sciences), and the geographic region the researcher is based in. ${ }^{3}$ First, we find an age cohort effect that points to greater use of English by younger scholars (see Figure 2). Researchers over 65 display the least propensity to use English, with an average estimate of only 51.3 percent of their journal submissions in English. In contrast, scholars aged 44 and below report submitting 10 percentage points more of their articles in English. This difference is also apparent in the percentage of scholars who report publishing exclusively in English. Specifically, scholars who report doing so make up 16.9 and 19.2 of the under 35 and 35-44 age groups, respectively, and only 8.6, 10.1 and 6.9 percent of the 45-54, 5565 , and over 65 groups, respectively.

These age differences can possibly be explained by two factors. First, it may be that as English has become more widespread as an international language, younger scholars are more comfortable writing in English, and therefore more likely to submit articles in English. Second, it could be due to older scholars tending to be at a point in their careers where they face fewer

\footnotetext{
${ }^{3}$ We would have also liked to include gender in our analysis, but the anonymized version of the dataset Springer provided us with does not have this information.
} 
pressures related to hiring and tenure; without these outside pressures, researchers may feel more at ease to publish in their local language, even if it means reaching a smaller audience.

Fig. 2 Proportion of recent journal submissions written in English by age groups

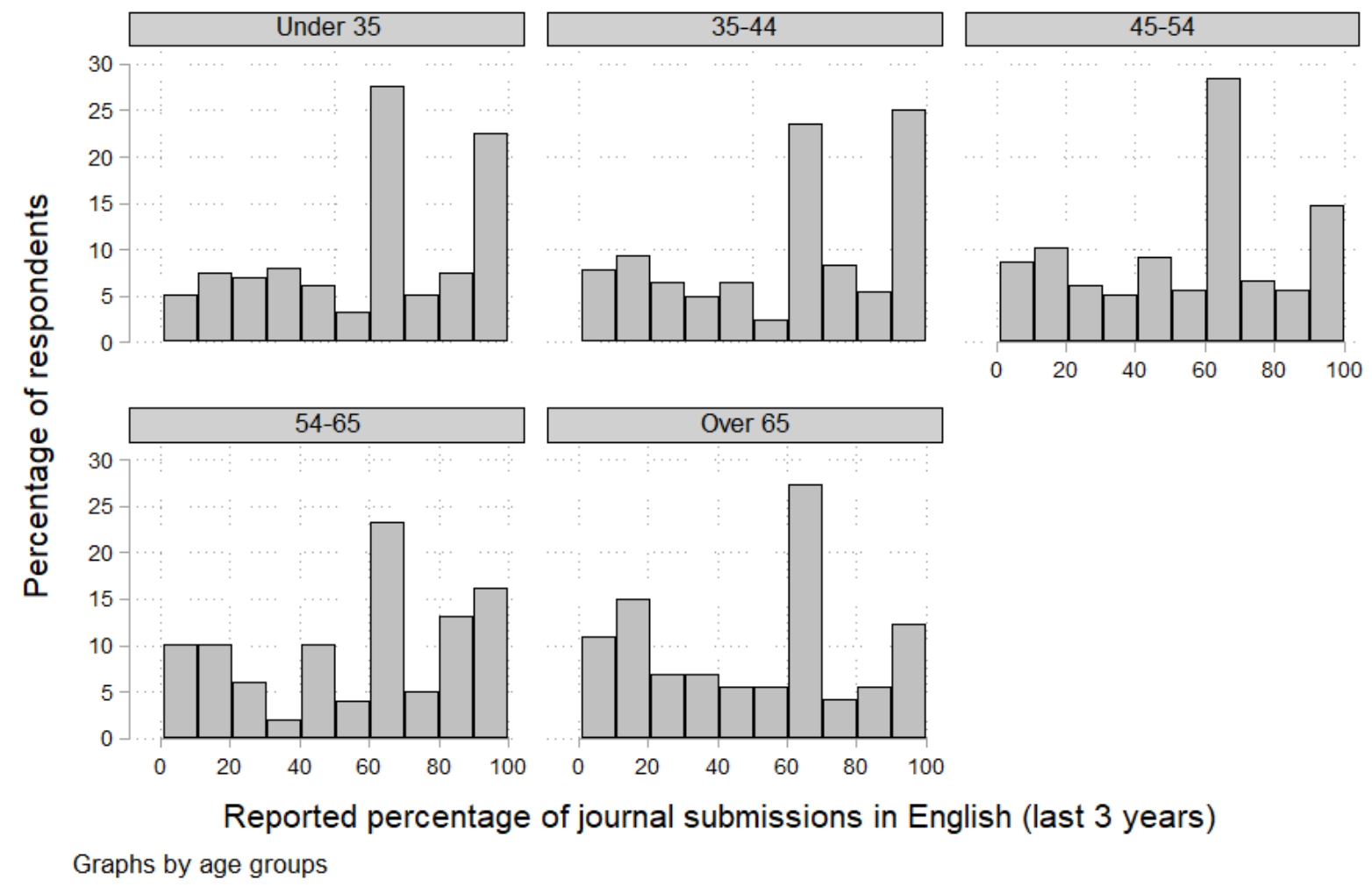

The next two factors we test -the perceived reputation of publishing in English ${ }^{4}$ and the perceived institutional pressure ${ }^{5}$ to do so (see Table 1) - are often cited in the literature as important 'push' factors of external pressures (e.g. tenure requirements that favour English publications (Lee and Lee 2013) and 'pull' factors of personal desire for a wider audience ${ }^{6}$ (Uzuner 2008). In particular, we find that the pull factor that publishing in English increases the reputation of one's work bears some salience. In fact, those who agree with the statement that publishing in English increases the reputation of their work submit 63 percent of their articles in English. In contrast, researchers who do not agree with this statement only author roughly 50 percent of their submissions in English. While this gap is large, even those agreeing that

\footnotetext{
${ }^{4}$ Respondents were asked to (dis)agree with "Publishing articles in International English-language journals would confer a greater reputation on my research." This variable serves as a proxy for many aspects of English's role in aiding career-advancement and reaching wider audiences.

${ }^{5}$ Specifically, respondents were asked "For your most recently published piece of research, did you experience any pressure from your funder to publish... in an international, English-language journal?" While respondents' perceptions of institutional pressure may not accurately reflect the realties of their institution, we include this measure as perceptions often shape actions.

${ }^{6}$ There is an additional push factor to publish in English; that is national research foundations such as the Swiss- or the Polish Research Councils encourage more and more the usage of English for grant submissions. In addition, many grants are awarded internationally. For example, the European Union is probably the largest grant awarding agency in the world and requires authors to submit in English. In addition, private foundations like the Rockefeller Foundation, or the Thyssen Foundation advertise their calls for research funding internationally and only allow submissions in English
} 
publishing in English increases the reputation of their work still author a large amount (over $35 \%$ ) of their submitted articles in other languages, indicating that other factors pushing (or pulling) them to publish in these languages are strong enough to sometimes outweigh the reputation that comes with English. In contrast, the push factor, perceived institutional pressure to publish in English, seems to play less of a role. In fact, the gap in the percentage of selfreported journal submissions in English is only 5 percentage points between those who report feeling institutional pressure and those who do not.

Fourth, when it comes to the place of employment, our bivariate results indicate that scholars who are employed by universities estimate that, on average, they write approximately 8 percentage points more of their submitted articles in English than those working for think-tanks, research centres, and in other non-university environments (see Table 1). Similarly, social scientists estimate to submit approximately 9 percentage points fewer articles in English than scholars in the natural sciences. While the disciplinary differences are similar to those observed by other studies (Giannoni 2008; Gingras 1984), the general dominance of English is less pronounced than had been found or assumed in previous studies (see, for example: Benfield and Howard 2000, p. 643; Giannoni p. 99); even in the natural sciences where English is most dominant, the average researcher submits almost a third of their articles in a language other than English.

Finally, there are some minor regional variations across the world in the prevalence of English, with Europeans reporting higher average percentages of submissions in English than their counterparts in the Americas and Asia (see Table 1). Europeans also reported greater rates of working exclusively in English (16.4\%) than do those in the Americas (6.6\%) or Asia (11.4\%). This trend lends some limited support to critical voices in the literature, who express concern that participating in English-dominated scientific discourse places a greater burden on those in developing nations (Canagarajah 1996; Curry and Lillis 2004). 
Stockemer \& Wigginton

Table 1: Percentage of recent journal submissions in English by institutional and work-related factors

\section{Mean Percent Standard Deviation N}

\section{Perceived reputation}

English increases the reputation of my research

63.08

29.20

578

English does not increase the reputation of my

51.70

28.91

268

research

\section{Perceived institutional pressure}

\begin{tabular}{|llll}
\hline Facing institutional pressure to publish in English & 62.25 & 28.97 & 322 \\
\hline Facing no institutional pressure to publish in English & 57.37 & 30.01 & 487
\end{tabular}

\section{Place of employment}

Researchers employed at a university

60.60

30.38

617

Employed either in the private sector or in a non-

52.82

26.98

167

university affiliated research center or think tank

\section{Discipline}

\begin{tabular}{llll} 
Natural sciences & 64.82 & 29.07 & 213 \\
\hline Social sciences & 55.79 & 31.03 & 203 \\
\hline Interdisciplinary studies & 57.06 & 28.65 & 197 \\
Geographic region & & & \\
Europe & 61.09 & 30.75 & 439 \\
\hline Americas (non-English-speaking countries) & 54.18 & 30.10 & 76 \\
\hline Asia $^{7}$ & 56.59 & 27.89 & 274 \\
\hline
\end{tabular}

In the multivariate analysis (see Table 2) we regress the self-reported percentage of journal submissions in English on our six independent variables. To do so, we use dummy variables. For the two original nominal variables age, region, and type of sciences, we create one less dummy variable than we have categories, with the hard sciences, Asia, and young researchers serving as the reference category, respectively.

Our model confirms that the belief in the higher reputation of English is the strongest determinant in favor of publishing in English. Specifically, we find that the model predicts a respondent agreeing that publishing in English will increase their work's reputation will report on average 10.1 percentage points more journal submissions in English than somebody who disagrees. In contrast, the corresponding 'push' factor of perceived institutional pressure, which was already quite weak in the bivariate realm, is not statistically significantly related to the selfreported percentage of journal submissions that are in English

\footnotetext{
${ }^{7}$ This includes one researcher from Africa
} 
The multivariate model further confirms the influence of a researcher's area of study and work environment. For example, the model predicts that individuals employed by a university have an approximately 6 percentage points higher chance to submit their research in English compared to those scholars who work in the private sector, a research center or a think tank. Similarly, the model, predicts that those who study the natural sciences submit approximately 8 percentage points more journal articles in English than researchers in the social sciences, and 6 percentage points more than researchers in the interdisciplinary sciences. Both of these differences may be reflective of a difference between those scholars who wish to engage a local or global audience (see: Gingras 1984). Natural science fields and university settings are becoming increasingly globalized; in order to reach the most possible fellow academics in the field scholars face pressure to publish their work in the most-used language. In contrast, those employed in non-academic settings might be more likely to be trying to engage local policymakers or audiences; hence their somewhat higher tendency to publish in the local language. In a similar vein, several social science sub-disciplines are centred on a particular country or cultural community (e.g. Quebec Studies), and as such scholars are likely to share a common language other than English within this subfield. ${ }^{8}$ Finally, Table 2 confirms that researchers aged 65 and over have a statistically significantly lower likelihood to write in English than younger scholars; our model predicts that, on average, they write about 12 percentage points fewer of their journal submissions in English compared to researchers under 35. Similarly for region, only European scholars seem more likely than those in the Americas to write in English, with the regression equation predicting that they submit nearly 10 percentage points more journal articles in English.

\footnotetext{
${ }^{8}$ This finding reflects Rocher and Stockemer's (2017) survey of French-speaking political scientists in Canada, which highlights that those who study International Relations publish a much higher percentage of their work in English than those who study Canadian and Québec politics.
} 
Table 2: OLS regression gauging researchers' self-reported percentage of publications in English

\begin{tabular}{|c|c|c|c|}
\hline & Coefficient & Std. Error & Significance \\
\hline English increases the reputation of my research & .101 & .023 & .000 \\
\hline $\begin{array}{l}\text { Perceived institutional pressure to publish in } \\
\text { English }\end{array}$ & .023 & .022 & .294 \\
\hline University employed & .065 & .026 & .013 \\
\hline Social Sciences & -.079 & .025 & .001 \\
\hline Interdisciplinary Sciences & -.060 & .030 & .049 \\
\hline Europe & .098 & .024 & .000 \\
\hline Americas & -.007 & .038 & .846 \\
\hline 35 to 44 & -.0004 & .029 & .988 \\
\hline $45-54$ & -.053 & .030 & .073 \\
\hline $55-64$ & -.043 & .036 & .241 \\
\hline $65+$ & -.119 & .042 & .005 \\
\hline Constant & .486 & .043 & .000 \\
\hline $\mathrm{R}^{2}$ & & .085 & \\
\hline $\mathrm{N}$ & & 767 & \\
\hline
\end{tabular}

To sum up, our article suggests that English is the dominant language of scientific communication. Yet, its dominance is not complete; rather, non-native speakers still submit almost 40 percent of their articles in a language other than English. Of course, there is some variation in this percentage. A researcher's propensity to submit journal articles in English increases with youth, university employment and research in the natural sciences, as well as the personal belief in the higher reputation of English publications. As our study only addresses motivations to publish in English, future research into motivations for publishing in other languages would be very useful in creating a more fulsome understanding of the determinates of publication language. For the future, we expect to see a continued increase in English publications. In particular, the greater use of English by younger scholars and possible increases to the prestige incentive may increase its dominance over time, this applies even more so, considering that there is a push to embrace English's dominance (see: Lublin 2018). In the present, however, while English is clearly the most-used language of scientific communication, publications in other languages remain commonplace. 


\section{References:}

Altbach, P. G. (2007). The imperial tongue: English as the dominating academic language. Economic and Political Weekly, 42(36), 3608-3611.

Benfield, J. R., \& Howard, K. M. (2000). The language of science. European Journal of CardioThoracic Surgery, 18(6), 642-648. https://doi.org/10.1016/S1010-7940(00)00595-9

Braine, G. (2002). Academic literacy and the nonnative speaker graduate student. Journal of English for Academic Purposes, 1(1), 59-68. https://doi.org/10.1016/S14751585(02)00006-1

Canagarajah, A. S. (1996). "Nondiscursive" requirements in academic publishing, material resources of periphery scholars, and the politics of knowledge production. Written Communication, 13(4), 435-472. https://doi.org/10.1177/0741088396013004001

Canagarajah, A. S. (1999). Resisting linguistic imperialism in English teaching. Oxford University Press.

Cho, S. (2004). Challenges of entering discourse communities through publishing in English: perspectives of nonnative-speaking doctoral students in the United States of America. Journal of Language, Identity \& Education, 3(1), 47-72. https://doi.org/10.1207/s15327701jlie0301 3

Curry, M. J., \& Lillis, T. (2004). Multilingual scholars and the imperative to publish in English: negotiating interests, demands, and rewards. TESOL Quarterly, 38(4), 663-688. https://doi.org/10.2307/3588284

Curry, M. J., \& Lillis, T. M. (2010). Academic research networks: Accessing resources for English-medium publishing. English for Specific Purposes, 29(4), 281-295. https://doi.org/10.1016/j.esp.2010.06.002

Duszak, A., \& Lewkowicz, J. (2008). Publishing academic texts in English: A Polish perspective. Journal of English for Academic Purposes, 7(2), 108-120. https://doi.org/10.1016/j.jeap.2008.03.001

Flowerdew, J. (2001). Attitudes of journal editors to nonnative speaker contributions. TESOL Quarterly, 35(1), 121-150. https://doi.org/10.2307/3587862

Flowerdew, J. (2008). Scholarly writers who use English as an additional language: What can Goffman's “stigma” tell us? Journal of English for Academic Purposes, 7(2), 77-86. https://doi.org/10.1016/j.jeap.2008.03.002

Flowerdew, J. (2012). Discourse community, legitimate peripheral participation, and the nonnative-English-speaking scholar. TESOL Quarterly, 34(1), 127-150. https://doi.org/10.2307/3588099

Flowerdew, J., \& Li, Y. (2009). English or Chinese? The trade-off between local and international publication among Chinese academics in the humanities and social sciences. Journal of Second Language Writing, 18(1), 1-16. https://doi.org/10.1016/j.jslw.2008.09.005

Giannoni, D. S. (2008). Medical writing at the periphery: The case of Italian journal editorials. Journal of English for Academic Purposes, 7(2), 97-107. https://doi.org/10.1016/j.jeap.2008.03.003

Gingras, Y. (1984). La valeur d'une langue dans un champ scientifique. Recherches sociographiques, 25(2), 285-296. https://doi.org/10.7202/056095ar

Google Scholar. (2018). Google Scholar Metrics. https://scholar.google.ca/citations?view op=top venues. Accessed 29 October 2018. 
Işık-Taş, E. E. (2018). Authorial identity in Turkish language and English language research articles in Sociology: The role of publication context in academic writers' discourse choices. English for Specific Purposes, 49, 26-38. https://doi.org/10.1016/j.esp.2017.10.003

Lee, H., \& Lee, K. (2013). Publish (in international indexed journals) or perish: Neoliberal ideology in a Korean university. Language Policy, 12(3), 215-230. https://doi.org/10.1007/s10993-012-9267-2

López-Navarro, I., Moreno, A. I., Quintanilla, M. Á., \& Rey-Rocha, J. (2015). Why do I publish research articles in English instead of my own language? Differences in Spanish researchers' motivations across scientific domains. Scientometrics, 103(3), 939-976. https://doi.org/10.1007/s11192-015-1570-1

Lublin, D. (2018). The Case for English. European Political Science, 17(3), 358-365. https://doi.org/10.1057/eps.2016.6

Rocher, F., \& Stockemer, D. (2017). Langue de publication des politologues francophones du Canada. Canadian Journal of Political Science, 50(1), 97-120. https://doi.org/10.1017/S0008423917000075

Uysal, H. H. (2014). Turkish academic culture in transition: Centre-based state policies and semiperipheral practices of research, publishing and promotion. In The Semiperiphery of Academic Writing: Discourses, Communities and Practices (pp. 165-188). https://doi.org/10.1057/9781137351197

Uzuner, S. (2008). Multilingual scholars' participation in core/global academic communities: A literature review. Journal of English for Academic Purposes, 7(4), 250-263. https://doi.org/10.1016/j.jeap.2008.10.007 